\title{
2012 CSHP National Awards Program Winners Programme national des prix 2012 de la SCPH : lauréats et lauréates
}

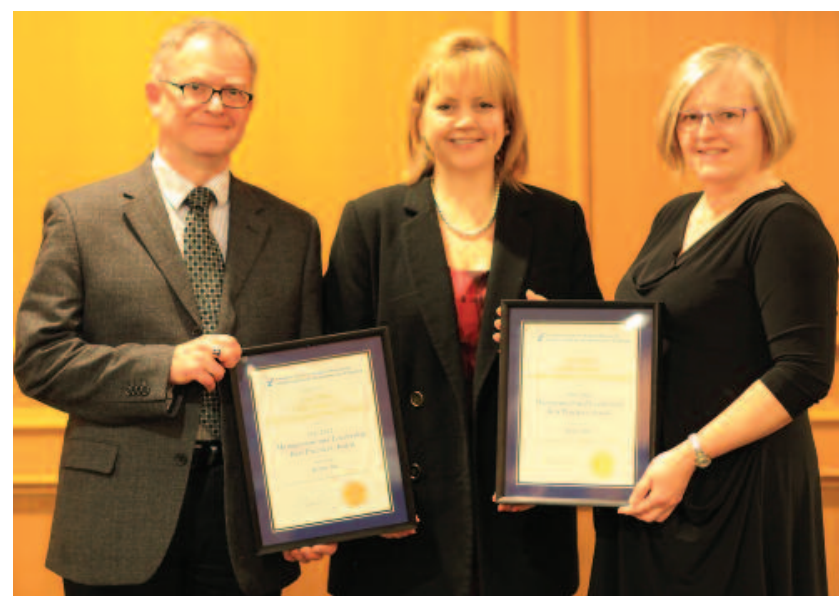

Management and Leadership Best Practices Award

Apotex Inc

Kevin Hall (left) and Donna Woloschuk (right) (recipients) with

Julie Berdusco (middle), Apotex (coauthors not present:

Colette Raymond and Nicholas Honcharik)

Organizational Restructuring of Regional Pharmacy Services to Facilitate Pharmacy Practice Model Change

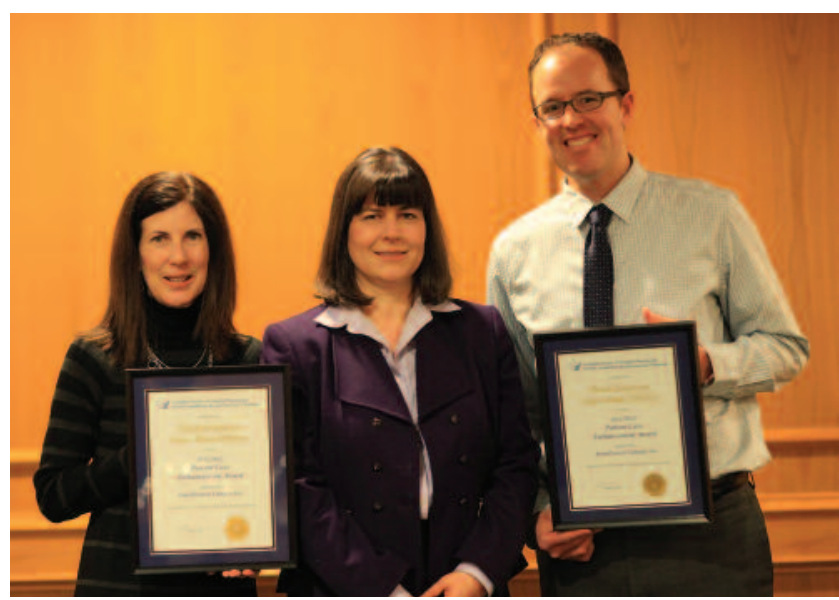

Patient Care Enhancement Award

AstraZeneca Canada Inc

Anne Marie Whelan (left) and Derek Jorgenson (right) (recipients) with Claudia Neuber (middle), AstraZeneca Canada Inc

Evaluating the Role of Pharmacist Teachers in Canadian Family Medicine Residency Programs: A Qualitative Analysis

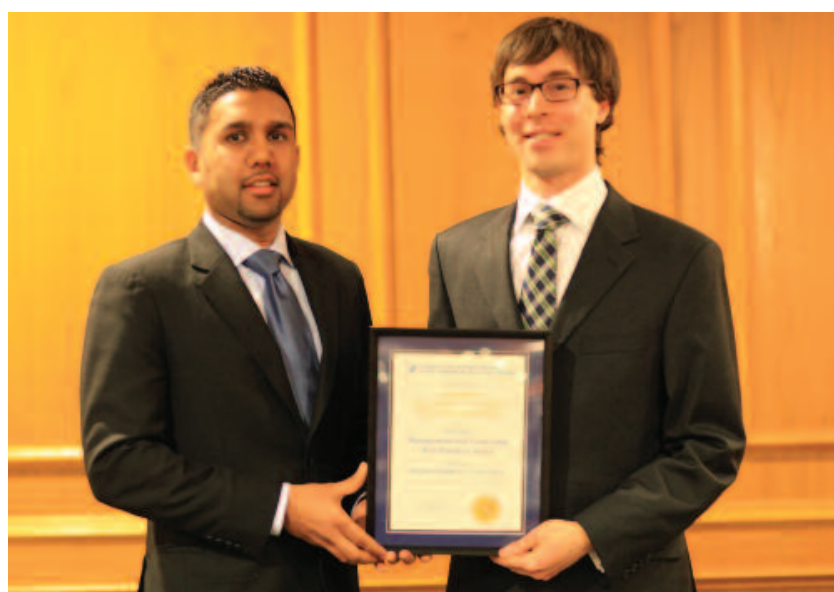

Management and Leadership Best Practices Award Hospira Healthcare Corporation Joseph Blais (right; recipient) with Rommel Gajadhar (left), Hospira Healthcare Corporation (coauthors not present: Ross Tsuyuki, Sheri Koshman, Dean Eurich, and Sheila Walter)

A Survey of Institutional Pharmacists' Involvement in and Attitudes towards Research

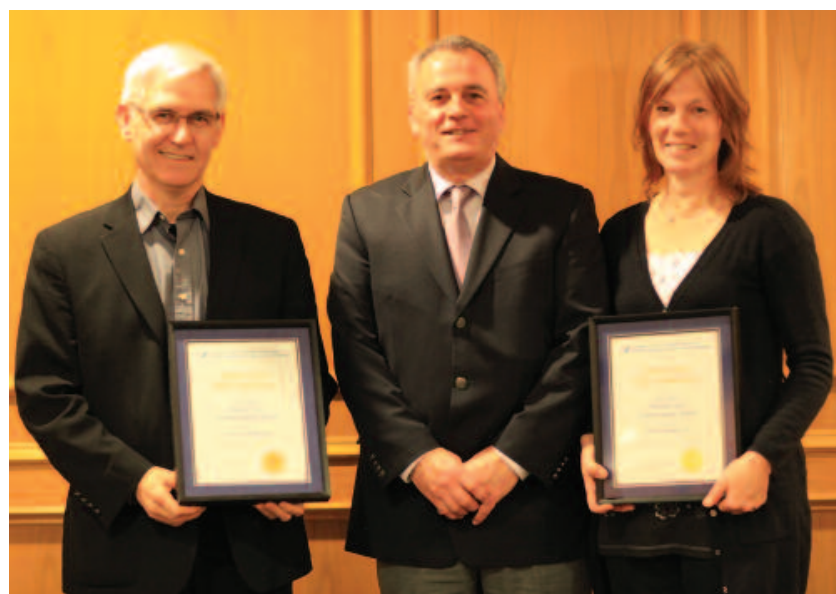

Patient Care Enhancement Award

TEVA Canada Ltd

Régis Vaillancourt (left) and Danica Irwin (right) (recipients) with Jim Lazenka (middle), TEVA Canada Ltd

Development and Implementation of a Pediatric Emergency Department (ED) Asthma Action Plan and Prescription (AAPP) 


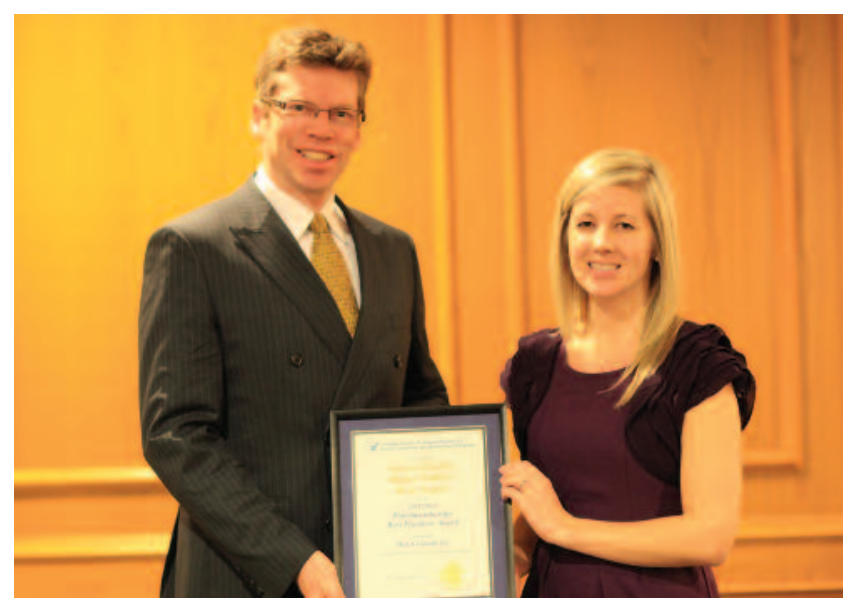

Pharmacotherapy Best Practices Award

Merck Canada Inc

Melissa Hawkins (right; recipient) with Peter Fields (left), Merck Canada Inc (coauthors not present: Michael LeBlanc and Gisia Pisegna)

A Pharmacist-Directed Toxicity Management Program for Patients Receiving

Capecitabine: Implementation and Evaluation

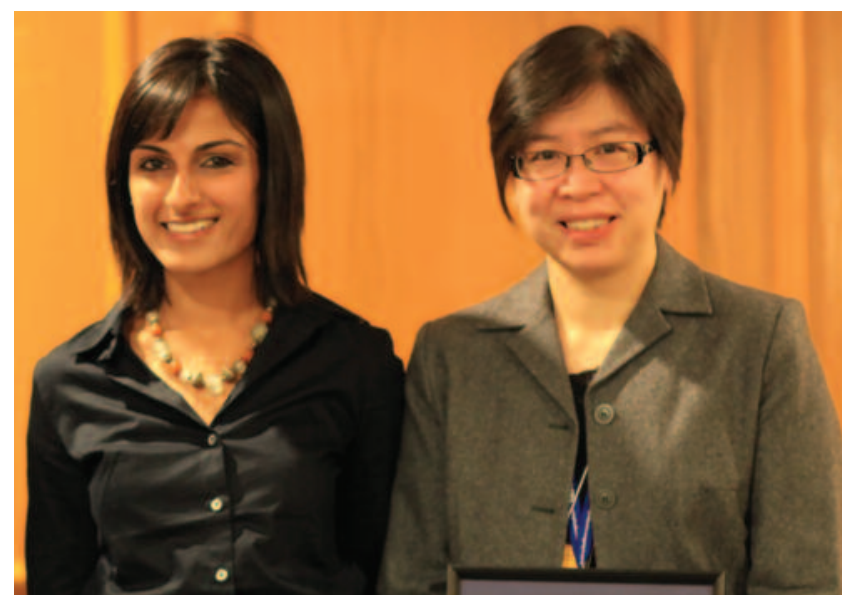

Safe Medication Practices Award

Baxter Corporation

Certina Ho (right; recipient) with Karimah Ajania (left),

Baxter Corporation

Extending Hospital-Based Medication Incident Reporting to Enhance

Medication Safety and Continuous Quality Assurance in Pharmacy

Practice

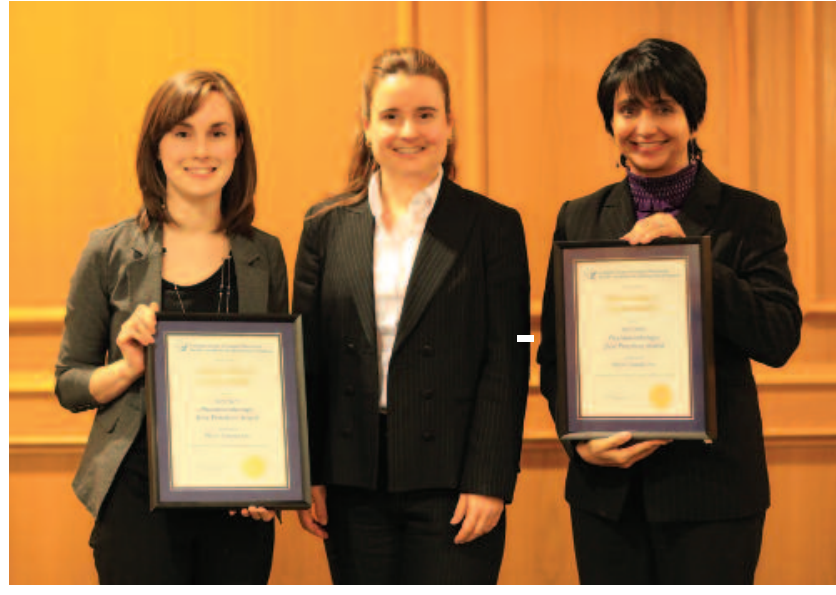

Pharmacotherapy Best Practices Award

Pfizer Canada Inc

Marion Elligson (left) and Sandra Walker (right) (recipients) with Genevieve Pelletier (middle), Pfizer Canada Inc

Evaluation of a Prospective Audit and Feedback Program in Critical Care: A Controlled Interrupted Time Series Analysis

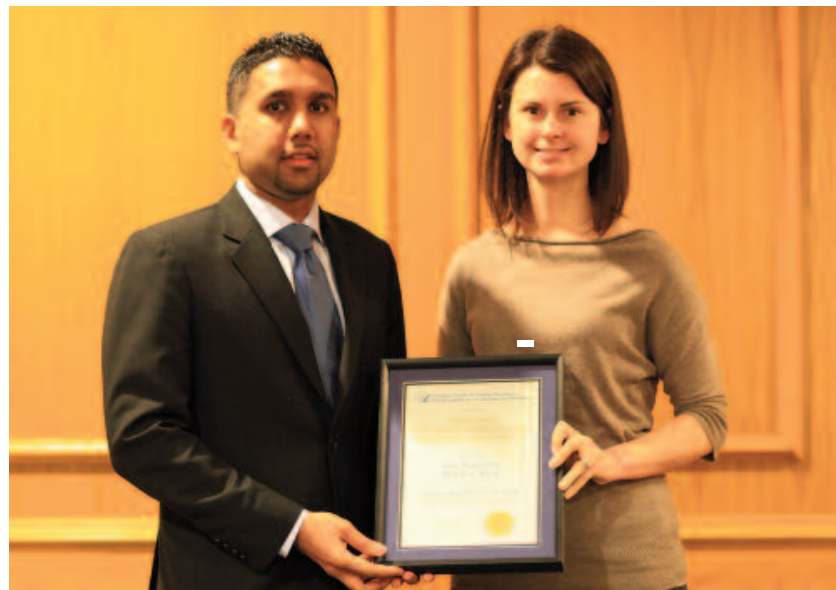

\section{Safe Medication Practices Award}

Hospira Healthcare Corporation

Rochelle Johnston (right; recipient) with Rommel Gajadhar (left), Hospira Healthcare Corporation (coauthors not present: Natalie LeBlanc, Leslie Manuel, Timothy MacLaggan, and Julie Levesque) Implementation and Evaluation of a Medication Reconciliation Tool on Internal Hospital Transfer 


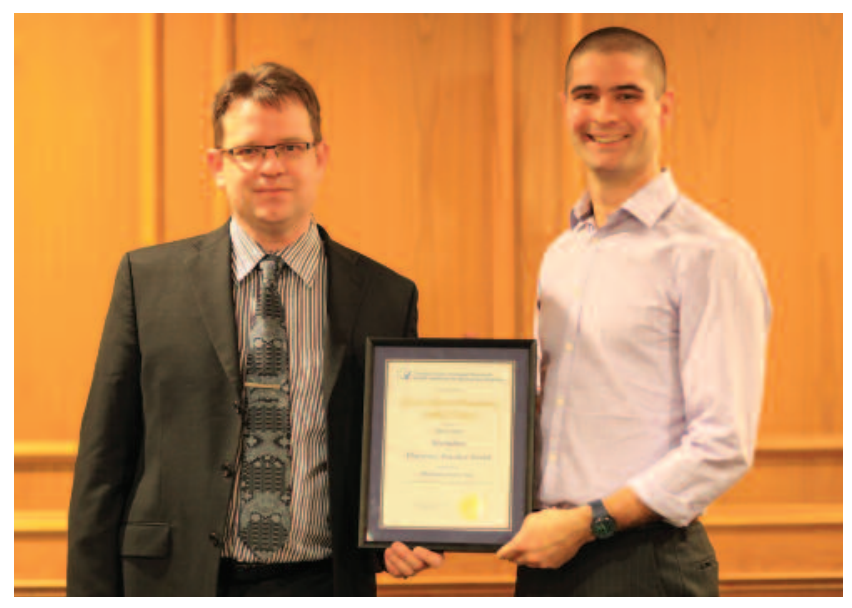

Specialties in Pharmacy Practice Award

Pharmascience Inc

Lucas Thorne-Humphrey (right; recipient) with Robert Labrosse (left),

Pharmascience (coauthor not present: Kathy Slayter)

Oseltamivir Pharmacokinetics in Morbid Obesity (OPTIMO Trial)

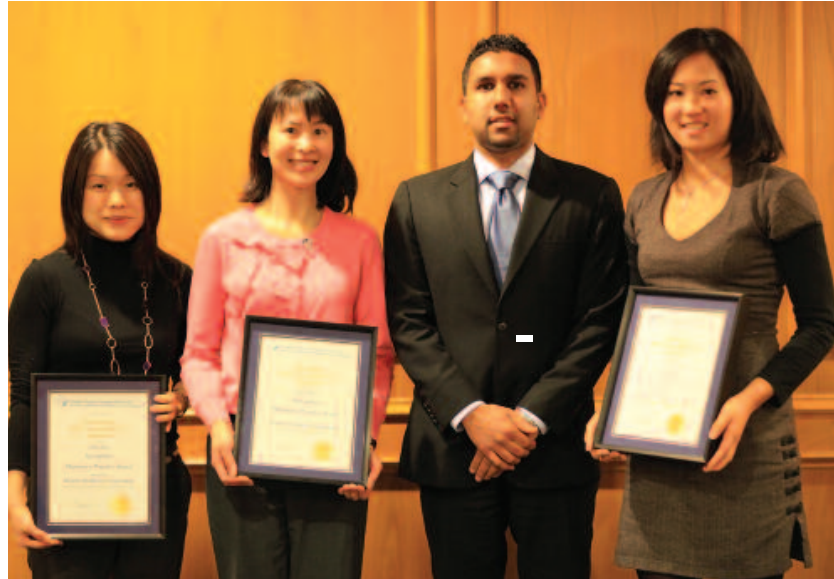

Specialties in Pharmacy Practice Award

Hospira Healthcare Corporation

Left to right: Pamela Ng (far left), Alice Tseng (middle left), and Alison Wong (far right) (recipients) with Rommel Gajadhar (middle right), Hospira Healthcare Corporation (coauthor not present: Jack Seki) Interactions between Antiretroviral Agents and Chemotherapy Regimens for the Treatment of Lymphoma: A Quick Reference Guide

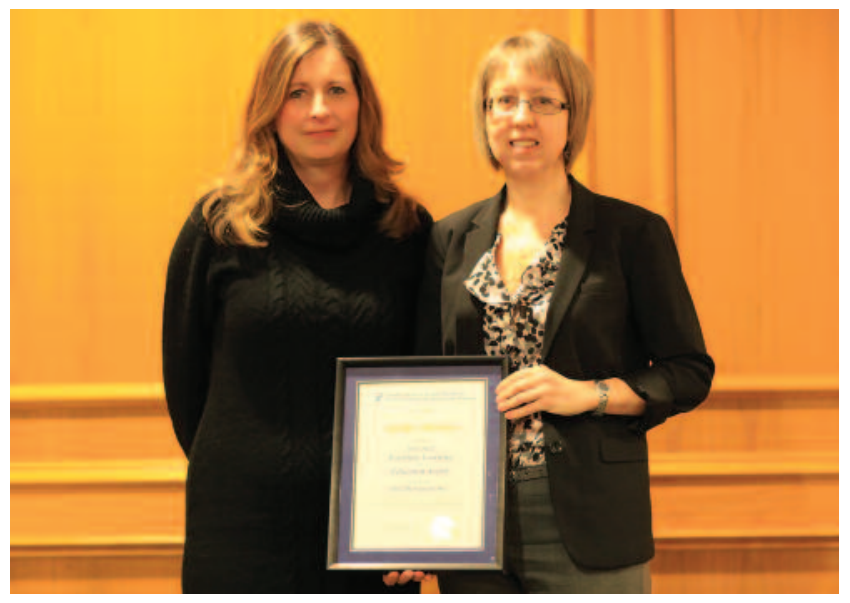

Teaching, Learning and Education Award

Eli Lilly Canada Inc

Jennifer Harrison (right; recipient) with Janice Munroe (left), CSHP

President, on behalf of Eli Lilly Canada Inc

An Online e-Learning Patient Education Tool for Solid Organ Transplant

Recipients 